\title{
The Determinants of Fishing Vessel Accident Severity
}

\author{
Di Jin \\ Marine Policy Center \\ Woods Hole Oceanographic Institution \\ Woods Hole, MA 02543
}

\begin{abstract}
The study examines the determinants of fishing vessel accident severity in the Northeastern United States using vessel accident data from the U.S. Coast Guard for 2001-2008. Vessel damage and crew injury severity equations were estimated separately utilizing the ordered probit model. The results suggest that fishing vessel accident severity is significantly affected by several types of accidents. Vessel damage severity is positively associated with loss of stability, sinking, daytime wind speed, vessel age, and distance to shore. Vessel damage severity is negatively associated with vessel size and daytime sea level pressure. Crew injury severity is also positively related to the loss of vessel stability and sinking.
\end{abstract}

February 5, 2014

Acknowledgements: This research was supported by the National Atmospheric and Oceanic Administration (NOAA) through the Cooperative Institute for the North Atlantic Region (CINAR) under NOAA Cooperative Agreement No. NA09OAR4320129 WHOI Subpoint 50. I would like to thank Chad Demarest, Mary Davis, Eric Thunberg, Wayne Talley, Andy Beet, and Hauke Kite-Powell for useful discussions, and an anonymous reviewer for his/her suggestions to improve the paper. 


\section{Introduction}

Commercial fishing is a dangerous occupation, and accidents are bound to happen given the operational environment within which fishing is conducted. In the United States, during 1992-2008, an annual average of 58 reported deaths occurred (128 deaths per 100,000 workers) in the fishing industry, compared with an average of 5,894 deaths (four per 100,000 workers) among all U.S. workers. Among the 504 U.S. commercial fishing deaths during 2000-2009, the majority occurred after a vessel accident (52\%) or a fall overboard (31\%). A quarter of the deaths occurred in the Northeast region. The fisheries with the highest fatality rates include Northeast multispecies groundfish fishery (600 per 100,000 full-time equivalent employees) and Atlantic scallop (425 per 100,000 full-time equivalent employees) (Lincoln and Lucas 2010).

The risk associated with commercial fishing may be defined as the product of the probability of an adverse outcome (event probability) and the severity of that outcome (Windle et al. 2008). The adverse outcome typically involves vessel damage and crew injury. The severity of vessel damage may vary from no damage to the loss of the vessel. The severity of crew injury may also vary from no injury to death. This study investigates the determinants of fishing vessel accident severity. Specifically, we examine fishing vessel accidents in the waters off the coast of Northeastern United States using the U.S. Coast Guard data from 2001 to 2008. Is the accident severity of a fishing vessel more likely to be greater for a certain type of vessel accident, vessel characteristic, weather condition, and season? The results of the investigation will be useful for policymakers that regulate the safety of fishing vessels, insurance companies that insure fishing vessels, and fisheries managers.

The paper extends our earlier studies of fishing vessel accidents in U.S. waters from 1981 to 2001. Jin et al. (2001) found that the probability of a total loss of the vessel was the greatest 
for a capsizing, followed by a sinking accident. Fire/explosions and capsizings were expected to incur the greatest number of crew fatalities: 3.5 and 3.8 for every 100 such accidents. For every 100 collisions, 2.1 nonfatal crew injuries were expected. The probability of a total loss and the expected number of crew fatalities varied inversely with the price of fish catches.

In another study, Jin and Thunberg (2005) investigated fishing vessel accident probability and vessel trip probability in North Atlantic U.S. EEZ fisheries using logit regression and daily data from 1981 to 2000. The study showed that fishing vessel accident probability declined over the study period. Higher wind speeds were associated with greater accident probability. Medium size vessels had the highest accident probability before 1994. Within the study region, accident probability was lower in southern New England and Mid-Atlantic waters than on Georges Bank and in the Gulf of Maine. Accidents were more likely to occur closer to shore than offshore. Accident probability was lower in spring and fall. Changes in fishery management in 1994 did not lead to a general increase in either accident or vessel trip probability. Although higher economic payoff (i.e., revenue of landings) induced more vessels to go fishing, this was not associated with an increase in accidents.

A comprehensive, multi-national review of fishing vessel safety studies can be found in Windle et al. (2008). Results of their study highlight the need for an improvement in assessment and for access to accurate and standardized statistics regarding fishing-related injuries and illnesses.

The paper is structured as follows. In Section 2, a model of the fishing vessel accident severity is presented. Data are discussed in Section 3. Sections 4 and 5 describe estimation procedures and results, respectively. Estimated marginal effects are presented in Section 6. Conclusions are set forth in Section 7. 


\section{The model}

According to vessel accident literature (Talley et al. 2006 and 2008), the fishing vessel accident damage severity $(D)$ is expected to vary with the type of vessel accident (a), vessel characteristics (c), type of vessel propulsion (p), type of vessel hull construction (h), weather condition (w), spatial location (s), and time of vessel accident (t), i.e.,

$$
D=f(\mathbf{a}, \mathbf{c}, \mathbf{p}, \mathbf{h}, \mathbf{w}, \mathbf{s}, \mathbf{t})
$$

Each vector on the right hand side of equation (1) consists of a number of measurement variables. The type of accident (a) includes many traditional variables found in Coast Guard statistics (i.e., allision, capsize, collision, explosion, fire, flooding, grounding, material failure, and sinking), ${ }^{1}$ several new variables describing post-ship-accident activities (i.e., vessel abandonment, vessel set adrift, loss of electrical power, and losses of vessel stability and maneuverability), and other new variables (i.e., vessel caused environmental damage and vessel requested emergency response). The vessel damage severity is expected to be greater if the vessel sank resulting from an accident. Otherwise, the a priori relationship between type of accident and $D$ is indeterminate.

Vessel characteristics (c) include vessel size (gross ton) and vessel age. The a priori sign of the relationship between accident vessel damage severity and vessel size is negative, as larger vessels are expected to be more seaworthy (e.g., less susceptible to adverse weather). The $a$ priori sign of the relationship between damage severity and vessel age is positive, since vessel structural failure is expected to increase with age.

\footnotetext{
${ }^{1}$ An allision accident occurs when a vessel strikes a stationary object (not another vessel) on the water surface. A collision accident occurs when a vessel strikes or was struck by another vessel on the water surface. A grounding accident occurs when the vessel is in contact with the sea bottom or a bottom obstacle. A material-failure accident typically involves equipment failure on board the vessel.
} 
Propulsion for a fishing vessel (p) includes diesel and gasoline engines. It is unclear, however, which of these propulsion sources are expected to result in greater vessel damage. A vessel's hull (h) may be constructed with aluminum, fiberglass, steel, or wood. Since steel is the strongest of these materials, it is expected that a vessel constructed with steel will incur less damage, all else held constant.

Weather condition (w) is represented by the daily maximum wind speed (m/s) and daily maximum sea level pressure $(\mathrm{hPa})$. The spatial variable (s) measures the distance to shore $(\mathrm{km})$. Time of vessel accident (t) includes time of day (nighttime versus daytime) and time of year (seasons). These variables capture the effects of changes in visibility as well as general weather conditions. Adverse weather and visibility are expected to increase the risk of a vessel accident, in turn, the vessel's damage severity. Replacing the vectors in equation (1) with the above described measurement variables (x), one obtains the fishing vessel accident damage severity reduced-form equation:

$$
D=F(\mathbf{x})
$$

Crew injury severity $(J)$ in a fishing vessel accident is expressed as a function of vessel damage severity $(D)$ and other factors in equation (1), such as accident type, i.e.,

$$
J=g(D, \mathbf{a}, \mathbf{c}, \mathbf{p}, \mathbf{h}, \mathbf{w}, \mathbf{s}, \mathbf{t})
$$

Vessel damage severity should have a non-negative effect on the crew injury severity given that a damaged vessel does not necessarily result in injured crew members. Also, more injuries are expected to occur under bad weather conditions. The a priori relationships between $J$ and vessel characteristics and other variables are unclear. Replacing the vectors in equation (3) by the variables used to measure them and rewriting, one obtains the crew injury severity reduced-form equation: 


$$
J=G(\mathbf{x})
$$

In the study, we develop two sets of regression models for accident severity, one for vessel damage $(D)$ and the other for crew injury $(J)$.

\section{Data}

Equations (2) and (4) are estimated utilizing detailed data of individual fishing vessel accidents that were investigated by the U.S. Coast Guard during the 8-year time period 20012008 and extracted from the Coast Guard's Marine Information for Safety and Law Enforcement (MISLE) database. The U.S. Coast Guard compiles vessel casualty and pollution statistics and maintains a computer database of detailed records on vessel accident and pollution events in U.S. waters. For the vessel accident data, each observation is a vessel involved in an accident. A long list of variables describes the vessel, time and location of the accident, and other related information (e.g., vessel type and flag). The name and format of the database have changed over the years. Between 1981 and 1991, the vessel casualty database was called CASMAIN. From 1992 to 2001, vessel casualty and pollution records were incorporated into a larger database called Marine Safety Information System (MSIS). Since December 2001, the database has transitioned to the MISLE information system. Three MISLE data tables were used to compile the two data sets (vessel damage and crew injury) for this study. The three data tables include: the Vessel Event Table (MisleVslEvents), the Vessel Table (MisleVessel), and Personal Injury Table (MisleInjury). Only US flagged fishing vessels in the Northeast region were included in the data sets.

Hourly wind speed and sea level pressure recorded from offshore buoys and nearshore weather stations were obtained from NOAA’s National Data Buoy Center. Daily maximum 
wind speeds and daily maximum pressure from each recording station were mapped to different fishing areas by assigning each area to the nearest weather recording station. The spatial feature of accident probability (distance from shore) is the distance from the center of each fishing area to the nearest coast. This was calculated using GIS software and the NMFS digital map of fishing areas.

Variables used in the vessel damage equation estimation, their specific measurements, and descriptive statistics (mean and standard deviation) appear in Table 1. The mean for the dependent variable, damage severity $(D)$, is 1.03 . Among the accident cases in the data set, $28.5 \%$ are classified as vessel "undamaged" $(D=0), 40.3 \%$ as vessel "damaged” $(D=1)$, and $31.2 \%$ as vessel "total constructive loss" or "actual total loss" $(D=2)$. The definition of dependent variable will be discussed further in the next section. The mean statistics for the explanatory variables reveal that the average size and age of a fishing vessel involved in an accident are 74 gross tons and 26.2 years, respectively. $66.2 \%$ and $30.7 \%$ of the accidents occurred at daytime and in winter, respectively. Most frequent accident types include environmental damage (19.4\%), material failure (14.9\%), sinking (11.4\%), and flooding (11.3\%). The average daily maximum wind speed and sea level pressure are $10.6 \mathrm{~m} / \mathrm{s}$ and 1,018.9 hPa.

Variables used in the crew injury equation estimation, their specific measurements, and descriptive statistics (mean and standard deviation) appear in Table 2. The mean for the dependent variable, crew injury severity $(J)$, is 0.127 . In the injury data set, $90.8 \%$ are classified as "no injury" $(J=0), 5.6 \%$ as "non-fatal injury" $(J=1)$, and 3.6\% as "fatal injury" $(J=2)$. Since both the vessel damage and the crew injury data sets are compiled from MISLE data tables, the mean statistics for the explanatory variables in the crew injury data set are very 
similar to those in the vessel damage data set. The average size and age of a fishing vessel involved in an accident are 73.5 gross tons and 25.9 years, respectively. $65.8 \%$ and $30.3 \%$ of the accidents occurred at daytime and in winter, respectively. Most frequent accident types include environmental damage (19.9), material failure (13.6\%), and flooding (11.7\%), sinking (11.5\%). The average daily maximum wind speed and sea level pressure are $10.7 \mathrm{~m} / \mathrm{s}$ and 1,018.8 hPa.

\section{Estimation procedures}

As noted above, we develop two sets of models for accident severity, one for vessel damage $(D)$ and the other for crew injury $(J)$. In both cases, we do not have specific information on accident severity. In the case of vessel damage, the accident vessel is classified as undamaged, damaged, or total loss. Similarly, the crew injury variable has the entries of no injury, non-fatal injury, or fatal injury. As a result, accident severity is a latent variable $S^{*}$, i.e.,

$$
S^{*}=\boldsymbol{\beta}^{\prime} \mathbf{x}+\varepsilon
$$

where $S^{*}=D^{*}$ or $J^{*}, \mathbf{x}$ is the set of independent variables, $\boldsymbol{\beta}$ is a vector of parameter coefficients to be estimated, and $\varepsilon$ is a normally distributed error term with zero mean and unit variance. Although we do not observe $S^{*}$, we do observe the ordinal accident severity variable $S$ which is positively related to actual accident severity. As mentioned above, in the vessel damage data set, $D$ has three entries, taking on the value of 0,1 , or $2: D=0$, if there is no accident damage to the vessel; $D=1$, if there is accident damage to the vessel; and $D=2$, if the accident damage to the vessel is classified as a total loss.

Similarly, $J$ has three entries in the crew injury data set, taking on the value of 0,1 , or 2 : $J=0$, if there is no injury associated with the vessel accident; $J=1$, if there are non-fatal injuries in the accident; and $J=2$, if the accident results in fatal injuries. 
In both cases, we have

$$
\begin{aligned}
& S=0 \quad \text { if } \quad S^{*} \leq 0 \\
& S=1 \quad \text { if } \quad 0<S^{*} \leq \mu \\
& S=2 \quad \text { if } \quad \mu<S^{*}
\end{aligned}
$$

where $S=D$ or $J, \mu$ is an estimable threshold parameter that distinguishes the accident severity.

Given the distribution assumptions on $\varepsilon$, the model defined in (6) is an ordered probit model with choice probabilities (Greene 1997):

$$
\begin{aligned}
& \operatorname{Porb}(S=0)=1-\Phi\left(\boldsymbol{\beta}^{\prime} \mathbf{x}\right) \\
& \operatorname{Porb}(S=1)=\Phi\left(\mu-\boldsymbol{\beta}^{\prime} \mathbf{x}\right)-\Phi\left(-\boldsymbol{\beta}^{\prime} \mathbf{x}\right) \\
& \operatorname{Porb}(S=2)=1-\Phi\left(\mu-\boldsymbol{\beta}^{\prime} \mathbf{x}\right)
\end{aligned}
$$

with $\mu>0$ to insure that all probabilities are positive. $\Phi$ is the CDF (cumulative distribution function) of the standard normal distribution. The Possible estimation bias from omission of relevant explanatory variables is addressed by including yearly binary variables (see Tables 1 and 2) in the estimations.

\section{Estimation results}

\section{Vessel Damage Severity}

Table 3 reports the results from ordered probit estimation for the $D^{*}$ in equation (5) using the data set on vessel damage. The table includes results for statistically significant explanatory variables and constant term. The chi-square statistic is large and statistically significant at the 0.01 level. The estimation results suggest that, among accident types, vessel damage severity is greater if a fishing vessel loses its stability, or is involved in a sinking accident. Other types of vessel accident that are associated with greater damage severities include flooding, fire, and material failure. The damage severity is expected to be greater for higher daytime wind speed 
and less with lower sea level pressure, suggesting that vessel damage severity is significantly affected by weather conditions. Note that under high pressure, weather is typically fair, skies cloudless. But under low pressure, rain, wind and inclimate conditions prevail.

The coefficients of the vessel characteristics variables suggest larger vessels are expected to sustain lower vessel damage, while older vessels are associated with greater vessel damage. Vessel damage severity is expected to be greater if the accident location further away from the shore.

Crew Injury Severity

Table 4 reports the results from ordered probit estimation for the $J^{*}$ in equation (5) using the data set on crew injury. As in the vessel damage model, the chi-square statistic is large and statistically significant at the 0.01 level. The estimation results suggest that crew injury severity is greater if a fishing vessel's stability is lost, or the vessel is involved in a sinking accident. In contrast, crew injury severity is lower if the vessel accident is limited to equipment failure. The crew injury severity is expected to be lower in the summer than in other seasons (Model I).

To assess directly the effects of vessel damage on crew injury, a second model is estimated using equation (3), and the results are also included in Table 4. According to Model II, there is a statistically significant positive relationship between the crew injury severity and vessel damage severity.

Note that to insure positive probabilities, the threshold parameter $\mu$ must be positive. As reported in Tables 3 and 4, the estimate of this parameter in both models are positive and highly significant. 


\section{Marginal effects}

Although the signs of the estimated ordered probit coefficients provide information on whether changes in given explanatory variables increase or lower the accident severity of a fishing vessel, they do not provide information on the extent to which the underlying accident severity probabilities change. For example, what is the impact of changes in the explanatory variables upon the probability of a fishing vessel accident sustaining no vessel damage $(D=0)$ versus the probability of sustaining vessel damage $(D=1)$.

For the ordered probit severity model, the marginal probability effects are:

$$
\begin{aligned}
& \partial \operatorname{Porb}(S=0) / \partial \mathbf{x}=-\phi\left(\boldsymbol{\beta}^{\prime} \mathbf{x}\right) \boldsymbol{\beta} \\
& \partial \operatorname{Porb}(S=1) / \partial \mathbf{x}=\left[\phi\left(-\boldsymbol{\beta}^{\prime} \mathbf{x}\right)-\phi\left(\mu-\boldsymbol{\beta}^{\prime} \mathbf{x}\right)\right] \boldsymbol{\beta} \\
& \partial \operatorname{Porb}(S=2) / \partial \mathbf{x}=\phi\left(\mu-\boldsymbol{\beta}^{\prime} \mathbf{x}\right) \boldsymbol{\beta}
\end{aligned}
$$

where $S=D$ or $J, \phi$ is the standard normal density function. When $\boldsymbol{\beta}$ 'x is a linear function of $x_{i}$ (a vector in $\mathbf{x})$, the partial derivative $\partial\left(\boldsymbol{\beta}^{\prime} \mathbf{x}\right) / \partial x_{i}$ is simply $\beta_{i}$, the coefficient of the explanatory variable $x_{i}$.

Suppose that an increase in $x_{i}$ increases fishing vessel accident severity. Then the coefficient of $x_{i}$ is positive. Thus via equation (8), an increase in $x_{i}$ increases the probability of the highest accident severity category, $S=2$, and decreases the probability of the lowest accident severity category, $S=0$. However, we don't know the effect of $x_{i}$ on the probability of the accident severity category, $S=1$. This probability depends upon the extent to which some fishing vessel accidents that are in the lower severity category $(S=1)$ shift into the highest category $(S=2)$, and the extent to which some accidents that are in the lowest category $(S=0)$ shift into higher severity category $(S=1)$. This is seen in equation (8) by the weighted difference in the two standard normal density functions. 


\section{Vessel Damage Probability}

Table 5 provides estimates of the marginal probabilities for the explanatory variables found in Table 3. If a fishing vessel loses its stability in an accident, it has the highest marginal probability of incurring a total loss (0.668). Other accident types with high marginal probability of a total loss include sinking (0.5313), flooding (0.3109), and fire (0.2985).

As expected, an increase in vessel age by one year is associated with an increase in the probability of total loss by 0.0026 . An increase in vessel size by 10 gross tons is associated with a reduction of total loss by $0.0101(-1.0101 / 100)$. If the accident location is one kilometer further offshore, the probability of total lost is higher by 0.0007 . For a $1 \mathrm{~m} / \mathrm{s}$ increase in daytime wind speed, the probability of total lost is higher by 0.009 . If the sea level pressure is $10 \mathrm{hPa}$ higher, the probability of total lost is lower by $0.0012(-0.1228 / 100)$.

\section{Crew Injury Probability}

Results of crew injury marginal probability estimations for the explanatory variables listed in Table 4 are shown in Table 6. According to Model I, if a fishing vessel loses its stability resulting from an accident, it has the highest marginal probability of incurring fatal injury (0.3191) among all types of accidents. Another accident type with high marginal probability of fatal injury is sinking (0.0494). If the accident occurs in the summer, the probability of fatal injury is lower by 0.015 . Results of Model II suggest that if an accident leads to a total loss of the vessel, the probability of fatal injury is higher by 0.082 .

\section{Conclusion}

This study has investigated determinants of the vessel damage and crew injury severities of fishing vessel accidents in the Northeastern United States. Detailed data of individual fishing 
vessel accidents for the 8-year time period 2001-2008 that were investigated by the U.S. Coast Guard were used to estimate two separate accident severity equations. The equations were estimated utilizing the ordered probit model.

The estimation results suggest that fishing vessel damage severity is positively associated with several types of accidents (e.g., loss of stability and sinking), daytime wind speed, vessel age, and distance to shore. Vessel damage severity is negatively associated with daytime sea level pressure and vessel size. If the accident vessel loses its stability, the probability of a total loss increases by 0.668 .

Crew injury severity is positively associated with loss of stability and sinking. Vessel damage severity significantly affects crew injury severity. If a fishing vessel loses its stability resulting from an accident, its marginal probability of incurring fatal injury is higher by 0.3191 . The injury severity is negatively related to material failure and summer season. Unlike in the case of vessel damages, the direct effects of weather variables (wind and sea level pressure) on crew injury severity are not statistically significant.

Unseaworthy vessels with inadequate stability have long been recognized as a main reason for the poor safety record in the commercial fishing industry (NRC 1991; USCG 1999). Results of the study indicate that vessel stability concerns should be a long term focus of safety managers and policy makers. While many of the results reported here are consistent with findings from previous studies, two points worth noticing. As noted, fire and explosions were identified as a main cause for crew fatalities on fishing vessels in the 1980s (Jin et al. 2001). Similar variables are not statistically significant in the present crew injury severity model, implying improvements in one aspect of vessel safety in recent years, which may be a result of relevant safety regulations governing fire-fighting systems on board fishing vessels (NRC 1991). 
Also, an earlier study (Jin and Thunberg 2005) found that fishing vessel accident probability was higher in summer and winter than in spring and fall, and that vessels were most likely to fish in the summer and least likely to fish in the winter, implying that more fatal injuries could occur in the busy fishing season as well. However, results of the present study show that crew injury severity is lower in the summer than other seasons, suggesting that more fatal injuries may occur during off-peak seasons. 


\section{References}

Greene, W.H. 1997. Econometric Analysis, 3rd Edition, Prentice Hall, Upper Saddle River, NJ.

Jin, D., H.L. Kite-Powell and W.K. Talley. 2001. The safety of commercial fishing: determinants of vessel total losses and injuries. Journal of Safety Research 32(2):209-228.

Jin, D. and E. Thunberg. 2005. An analysis of fishing vessel accidents in fishing areas off the northeastern United States. Safety Science 43(8):523-540.

Lincoln, J. and D. Lucas. 2010. Commercial Fishing Deaths - United States, 2000-2009. MMWR Morbidity and Mortality Weekly Report 59(27):842-845.

National Research Council (NRC). 1991. Fishing Vessel Safety: Blueprint for a National Program. National Academy Press, Washington, DC.

Talley, W.K., D. Jin and H. Kite-Powell. 2006. Determinants of the severity of passenger vessel accidents. Maritime Policy and Management 33(2):173-186.

Talley, W.K., D. Jin and H. Kite-Powell. 2008. Determinants of the damage cost and injury severity of ferry vessel accidents. WMU Journal of Maritime Affairs 7(1):175-188.

U.S. Coast Guard (USCG). 1999. Dying to Fish, Living to Fish: Fishing Vessel Casualty Task Force Report. U.S. Government Printing Office, Washington, DC.

Windle, M.J.S., B. Neis, S. Bornstein, M. Binkley, P. Navarro. 2008. Fishing occupational health and safety: A comparison of regulatory regimes and safety outcomes in six countries. Marine Policy 32 (2008) 701-710. 
Table 1. Fishing vessel accident damage: variable definitions and descriptive statistics

\begin{tabular}{|c|c|c|c|}
\hline Variable & Measurement & Mean & Std.Dev. \\
\hline \multicolumn{4}{|l|}{ Dependent Variable } \\
\hline Damage severity & $\begin{array}{l}0 \text { if vessel undamaged (28.5\%) } \\
1 \text { if vessel damaged (40.3\%) } \\
2 \text { if vessel total loss (31.2\%) }\end{array}$ & 1.0262 & 0.7725 \\
\hline \multicolumn{4}{|l|}{ Explanatory Variable } \\
\hline \multicolumn{4}{|l|}{ Type of accident } \\
\hline Abandonment & 1 if vessel abandoned, 0 otherwise & 0.0384 & 0.1921 \\
\hline Adrift & 1 if vessel set adrift, 0 otherwise & 0.0075 & 0.0862 \\
\hline Allision & 1 if an allision, 0 otherwise & 0.0327 & 0.1780 \\
\hline Capsize & 1 if a capsize, 0 otherwise & 0.0187 & 0.1356 \\
\hline Collision & 1 if a collision, 0 otherwise & 0.0580 & 0.2338 \\
\hline Emergency response & $\begin{array}{l}1 \text { if vessel requested emergency response, o } \\
\text { otherwise }\end{array}$ & 0.0449 & 0.2072 \\
\hline $\begin{array}{l}\text { Environmental } \\
\text { damage }\end{array}$ & $\begin{array}{l}1 \text { if vessel caused environmental damage, } 0 \\
\text { otherwise }\end{array}$ & 0.1936 & 0.3953 \\
\hline Explosion & 1 if an explosion vessel accident, 0 otherwise & 0.0019 & 0.0432 \\
\hline Fire & 1 if a fire vessel accident, 0 otherwise & 0.0421 & 0.2009 \\
\hline Flooding & 1 if a flooding vessel accident, 0 otherwise & 0.1132 & 0.3170 \\
\hline Grounding & 1 if a grounding vessel accident, 0 otherwise & 0.0795 & 0.2707 \\
\hline $\begin{array}{l}\text { Loss of electrical } \\
\text { power }\end{array}$ & 1 if vessel lost electrical power, 0 otherwise & 0.0084 & 0.0914 \\
\hline Loss of stability & 1 if vessel lost stability, 0 otherwise & 0.0084 & 0.0914 \\
\hline Maneuverability & $\begin{array}{l}1 \text { if vessel had a maneuverability problem, } 0 \\
\text { otherwise }\end{array}$ & 0.0776 & 0.2677 \\
\hline Material failure & 1 if a material-failure accident, 0 otherwise & 0.1487 & 0.3560 \\
\hline Sinking & 1 if a sinking accident, 0 otherwise & 0.1141 & 0.3181 \\
\hline \multicolumn{4}{|l|}{ Vessel characteristics } \\
\hline Vessel gross ton & vessel size in gross tons & 74.06 & 65.18 \\
\hline Vessel age & vessel age in years & 26.17 & 11.93 \\
\hline \multicolumn{4}{|l|}{ Type of propulsion } \\
\hline Diesel engine & 1 if vessel is under diesel propulsion, 0 otherwise & 0.4967 & 0.5002 \\
\hline Gasoline engine & 1 if vessel is under gasline propulsion, 0 otherwise & 0.0094 & 0.0963 \\
\hline \multicolumn{4}{|c|}{ Type of hull construction } \\
\hline Aluminum hull & 1 if aluminum hull construction, 0 otherwise & 0.0056 & 0.0747 \\
\hline Fiberglass hull & 1 if fiberglass hull construction, 0 otherwise & 0.2301 & 0.4211 \\
\hline Steel hull & 1 if steel hull construction, 0 otherwise & 0.3368 & 0.4728 \\
\hline Wood hull & 1 if wood hull construction, 0 otherwise & 0.3255 & 0.4688 \\
\hline \multicolumn{4}{|l|}{ Weather condition } \\
\hline Wind speed & daily maximum wind speed in $\mathrm{m} / \mathrm{s}$ & 10.61 & 4.05 \\
\hline
\end{tabular}




\begin{tabular}{|c|c|c|c|}
\hline Sea level pressure & daily maximum sea level pressure in $\mathrm{hPa}$ & $1,018.86$ & 7.55 \\
\hline \multicolumn{4}{|l|}{ Spatial variable } \\
\hline $\begin{array}{l}\text { Distance to shore } \\
\text { Tine of accident }\end{array}$ & $\mathrm{km}$ & 47.12 & 45.01 \\
\hline Night & 1 if nighttime, 0 otherwise & 0.3377 & 0.4731 \\
\hline Daytime & 1 if daytime, 0 otherwise & 0.6623 & 0.4731 \\
\hline \multicolumn{4}{|l|}{ Season } \\
\hline Spring & 1 if spring, 0 otherwise & 0.1833 & 0.3871 \\
\hline Summer & 1 if summer, 0 otherwise & 0.2451 & 0.4303 \\
\hline Fall & 1 if fall, 0 otherwise & 0.2647 & 0.4414 \\
\hline Winter & 1 if winter, 0 otherwise & 0.3068 & 0.4614 \\
\hline \multicolumn{4}{|l|}{ Year } \\
\hline 2001 & 1 if year 2001, 0 otherwise & 0.0430 & 0.2030 \\
\hline 2002 & 1 if year 2002, 0 otherwise & 0.1843 & 0.3879 \\
\hline 2003 & 1 if year 2003, 0 otherwise & 0.1843 & 0.3879 \\
\hline 2004 & 1 if year 2004, 0 otherwise & 0.1759 & 0.3809 \\
\hline 2005 & 1 if year 2005, 0 otherwise & 0.2376 & 0.4258 \\
\hline 2006 & 1 if year 2006, 0 otherwise & 0.1225 & 0.3281 \\
\hline 2007 & 1 if year 2007, 0 otherwise & 0.0262 & 0.1598 \\
\hline 2008 & 1 if year 2008, 0 otherwise & 0.0262 & 0.1598 \\
\hline
\end{tabular}


Table 2. Fishing vessel accident crew injury: variable definitions and descriptive statistics

\begin{tabular}{|c|c|c|c|}
\hline Variable & Measurement & Mean & Std.Dev. \\
\hline \multicolumn{4}{|l|}{ Dependent Variable } \\
\hline \multirow[t]{3}{*}{ Injury severity } & 0 if no vessel accident injuries (90.8\%) & 0.1273 & 0.4271 \\
\hline & 1 if non-fatal vessel accident injuries (5.6\%) & & \\
\hline & 2 if fatal vessel accident injuries (3.6\%) & & \\
\hline \multicolumn{4}{|l|}{ Explanatory Variable } \\
\hline \multicolumn{4}{|l|}{ Type of accident } \\
\hline Abandonment & 1 if vessel abandoned, 0 otherwise & 0.0290 & 0.1680 \\
\hline Adrift & 1 if vessel set adrift, 0 otherwise & 0.0103 & 0.1010 \\
\hline Allision & 1 if an allision, 0 otherwise & 0.0318 & 0.1756 \\
\hline Capsize & 1 if a capsize, 0 otherwise & 0.0187 & 0.1356 \\
\hline Collision & 1 if a collision, 0 otherwise & 0.0590 & 0.2357 \\
\hline Emergency response & $\begin{array}{l}1 \text { if vessel requested emergency response, o } \\
\text { otherwise }\end{array}$ & 0.0524 & 0.2230 \\
\hline Environmental damage & $\begin{array}{l}1 \text { if vessel caused environmental damage, } 0 \\
\text { otherwise }\end{array}$ & 0.1994 & 0.3998 \\
\hline Explosion & 1 if an explosion vessel accident, 0 otherwise & 0.0037 & 0.0611 \\
\hline Fire & 1 if a fire vessel accident, 0 otherwise & 0.0365 & 0.1877 \\
\hline Flooding & 1 if a flooding vessel accident, 0 otherwise & 0.1170 & 0.3216 \\
\hline Grounding & 1 if a grounding vessel accident, 0 otherwise & 0.0843 & 0.2779 \\
\hline Loss of electrical power & 1 if vessel lost electrical power, 0 otherwise & 0.0084 & 0.0915 \\
\hline Loss of stability & 1 if vessel lost stability, 0 otherwise & 0.0103 & 0.1010 \\
\hline Maneuverability & $\begin{array}{l}1 \text { if vessel had a maneuverability problem, } 0 \\
\text { otherwise }\end{array}$ & 0.0740 & 0.2618 \\
\hline Material failure & 1 if a material-failure accident, 0 otherwise & 0.1358 & 0.3427 \\
\hline Sinking & 1 if a sinking accident, 0 otherwise & 0.1152 & 0.3194 \\
\hline \multicolumn{4}{|l|}{ Vessel characteristics } \\
\hline Vessel gross ton & vessel size in gross tons & 73.48 & 66.25 \\
\hline Vessel age & vessel age in years & 25.89 & 12.30 \\
\hline \multicolumn{4}{|l|}{ Type of propulsion } \\
\hline Diesel engine & $\begin{array}{l}1 \text { if vessel is under diesel propulsion, } 0 \\
\text { otherwise } \\
1 \text { if vessel is under gasline propulsion }\end{array}$ & 0.5037 & 0.5002 \\
\hline Gasoline engine & $\begin{array}{l}\text { 1 if vessel is under gasline propulsion, } 0 \\
\text { otherwise }\end{array}$ & 0.0084 & 0.0915 \\
\hline \multicolumn{4}{|l|}{ Type of hull construction } \\
\hline Aluminum hull & 1 if aluminum hull construction, 0 otherwise & 0.0084 & 0.0915 \\
\hline Fiberglass hull & 1 if fiberglass hull construction, 0 otherwise & 0.2088 & 0.4066 \\
\hline
\end{tabular}




\begin{tabular}{|c|c|c|c|}
\hline Steel hull & 1 if steel hull construction, 0 otherwise & 0.3483 & 0.4767 \\
\hline Wood hull & 1 if wood hull construction, 0 otherwise & 0.3202 & 0.4668 \\
\hline \multicolumn{4}{|l|}{ Weather condition } \\
\hline Wind speed & daily maximum wind speed in $\mathrm{m} / \mathrm{s}$ & 10.68 & 3.93 \\
\hline Sea level pressure & daily maximum sea level pressure in $\mathrm{hPa}$ & $1,018.75$ & 7.98 \\
\hline \multicolumn{4}{|l|}{ Spatial variable } \\
\hline $\begin{array}{l}\text { Distance to shore } \\
\text { Tine of accident }\end{array}$ & $\mathrm{km}$ & 47.15 & 45.03 \\
\hline Night & 1 if nighttime, 0 otherwise & 0.3418 & 0.4745 \\
\hline Daytime & 1 if daytime, 0 otherwise & 0.6582 & 0.4745 \\
\hline \multicolumn{4}{|l|}{ Season } \\
\hline Spring & 1 if spring, 0 otherwise & 0.1845 & 0.3880 \\
\hline Summer & 1 if summer, 0 otherwise & 0.2481 & 0.4321 \\
\hline Fall & 1 if fall, 0 otherwise & 0.2640 & 0.4410 \\
\hline Winter & 1 if winter, 0 otherwise & 0.3034 & 0.4599 \\
\hline \multicolumn{4}{|l|}{ Year } \\
\hline 2001 & 1 if year 2001, 0 otherwise & 0.0440 & 0.2052 \\
\hline 2002 & 1 if year 2002, 0 otherwise & 0.1807 & 0.3850 \\
\hline 2003 & 1 if year 2003, 0 otherwise & 0.1835 & 0.3873 \\
\hline 2004 & 1 if year 2004, 0 otherwise & 0.1770 & 0.3818 \\
\hline 2005 & 1 if year 2005, 0 otherwise & 0.2294 & 0.4206 \\
\hline 2006 & 1 if year 2006, 0 otherwise & 0.1236 & 0.3293 \\
\hline 2007 & 1 if year 2007, 0 otherwise & 0.0309 & 0.1731 \\
\hline 2008 & 1 if year 2008, 0 otherwise & 0.0309 & 0.1731 \\
\hline
\end{tabular}


Table 3. Fishing vessel accident damage severity equation estimates

\begin{tabular}{|c|c|}
\hline Explanatory variable & $\begin{array}{r}\text { Coefficient } \\
(t \text {-value })\end{array}$ \\
\hline \multicolumn{2}{|l|}{ Type of accident } \\
\hline Fire & $\begin{array}{c}0.7819^{* * *} \\
(3.98)\end{array}$ \\
\hline Flooding & $\begin{array}{c}0.8233^{* * *} \\
(6.35)\end{array}$ \\
\hline Material failure & $\begin{array}{c}0.2946^{* * *} \\
(2.65)\end{array}$ \\
\hline Sinking & $\begin{array}{c}1.4491^{* * *} \\
(9.68)\end{array}$ \\
\hline Loss of stability & $\begin{array}{c}2.2163^{* * *} \\
(3.88)\end{array}$ \\
\hline \multicolumn{2}{|l|}{ Weather condition } \\
\hline Daytime×Wind speed & $\begin{array}{c}0.0264^{* *} \\
(2.19)\end{array}$ \\
\hline Daytime×Sea level pressure & $\begin{array}{c}-0.3591^{* *} \\
(-2.37)\end{array}$ \\
\hline \multicolumn{2}{|l|}{ Vessel Characteristics } \\
\hline Gross ton & $\begin{array}{c}-2.9545^{* * *} \\
(-4.59)\end{array}$ \\
\hline Age & $\begin{array}{c}0.0077^{* *} \\
(2.20)\end{array}$ \\
\hline \multicolumn{2}{|l|}{ Spatial variable } \\
\hline Distance to shore & $\begin{array}{c}0.0020^{* *} \\
(2.06)\end{array}$ \\
\hline Constant & $\begin{array}{c}0.3123^{* *} \\
(2.28)\end{array}$ \\
\hline Ordered probit parameter, $\mu$ & $\begin{array}{c}1.2341^{* * *} \\
(21.56)\end{array}$ \\
\hline Number of observations & 836 \\
\hline Chi-square statistic & $197.589^{* * *}$ \\
\hline
\end{tabular}

$*, * *$ and $* * *$ denote significance at $10,5,1 \%$ significance level, respectively. Gross ton is in 1,000 ton.

Sea level pressure is in $\mathrm{hPa} / 1000$. 
Table 4. Fishing vessel crew injury severity equation estimates

\begin{tabular}{lcc}
\hline Explanatory variable & $\begin{array}{c}\text { Model I } \\
\text { Coefficient } \\
\text { (t-value) }\end{array}$ & $\begin{array}{c}\text { Model II } \\
\text { Coefficient } \\
\text { (t-value) }\end{array}$ \\
\hline Type of accident & $-0.5475^{* *}$ & $-0.5364^{* *}$ \\
Material failure & $(-2.44)$ & $(-2.24)$ \\
Sinking & $0.5179^{* * *}$ & - \\
Loss of stability & $(3.62)$ & $1.1461^{* * *}$ \\
Vessel damage severity & $1.5239^{* * *}$ & $(2.92)$ \\
vessel total loss & $(4.08)$ & $1.1628^{* * *}$ \\
Season & - & $(9.61)$ \\
Summer & & $-0.2707^{*}$ \\
Constant & $-0.2585^{*}$ & $(-1.86)$ \\
Ordered probit parameter, $\mu$ & $(-1.91)$ & $-1.7985^{* * *}$ \\
Number of observations & $-1.3305^{* * *}$ & $(-18.13)$ \\
Chi-square statistic & $(-19.12)$ & $0.5900^{* * *}$ \\
\hline
\end{tabular}

$*$, ** and $* * *$ denote significance at 10, 5, 1\% significance level, respectively. 
Table 5. Marginal fishing vessel accident damage severity probabilities

\begin{tabular}{lrrr}
\hline Explanatory variable & $D=0$ & $D=1$ & $D=2$ \\
\hline Type of accident & & & \\
Fire & -0.1827 & -0.1158 & 0.2985 \\
Flooding & -0.2000 & -0.1110 & 0.3109 \\
Material failure & -0.0865 & -0.0192 & 0.1057 \\
Sinking & -0.2773 & -0.2539 & 0.5313 \\
Loss of stability & -0.2543 & -0.4137 & 0.6680 \\
Weather condition & & & \\
Daytime×Wind speed & -0.0084 & -0.0007 & 0.0090 \\
Daytime×Sea level pressure & 0.1138 & 0.0090 & -0.1228 \\
Vessel Characteristics & & & \\
Gross ton & 0.9363 & 0.0737 & -1.0101 \\
Age & -0.0024 & -0.0002 & 0.0026 \\
Spatial variable & & & \\
Distance to shore & -0.0006 & -0.0000 & 0.0007 \\
\hline
\end{tabular}


Table 6. Marginal fishing vessel crew injury severity probabilities

\begin{tabular}{lcccccc}
\hline Explanatory variable & \multicolumn{2}{c}{$J=0$} & \multicolumn{2}{c}{$J=1$} & \multicolumn{2}{c}{$J=2$} \\
& Model I & Model II & Model I & Model II & Model I & Model II \\
\hline Type of accident & & & & & & \\
Material failure & 0.0626 & 0.0459 & -0.0376 & -0.0319 & -0.0250 & -0.0140 \\
Sinking & -0.1017 & - & 0.0523 & - & 0.0494 & - \\
Loss of stability & -0.4663 & -0.2737 & 0.1472 & 0.1369 & 0.3191 & 0.1368 \\
Vessel damage severity & & & & & & \\
vessel total loss & - & -0.1954 & - & 0.1135 & - & 0.0820 \\
Season & & & & & & \\
Summer & 0.0357 & 0.0282 & -0.0207 & -0.0191 & -0.0150 & -0.0090 \\
\hline
\end{tabular}

